\title{
Prevalence and Characteristics of Treatment-Resistant Hypertension among Hypertensive Japanese Outpatients
}

\author{
Keisuke Okamura, Hidenori Urata \\ Department of Cardiovascular Diseases, Fukuoka University Chikushi Hospital, Chikushino, Japan \\ Email: okamurakmd@cis.fukuoka-u.ac.jp
}

Received 28 July 2015; accepted 7 September 2015; published 10 September 2015

Copyright (C) 2015 by authors and Scientific Research Publishing Inc.

This work is licensed under the Creative Commons Attribution International License (CC BY). http://creativecommons.org/licenses/by/4.0/

(c) (†) Open Access

\begin{abstract}
Aims: To retrospectively investigate the prevalence and characteristics of treatment-resistant hypertension (R-HT) among consecutive hypertensive outpatients, since patients with R-HT are candidates for catheter-based renal sympathetic denervation (RD). Methods: Consecutive hypertensive outpatients $(n=999)$ were recruited in our hospital. $R-H T$ patients who were candidates for RD had clinic systolic blood pressure $>160 \mathbf{~ m m H g}$ despite taking three or more antihypertensive drugs including at least one diuretics at higher than standard doses. Results: Our survey indicated that only 26 patients $(2.6 \%)$ were potential candidates for renal denervation. Candidates for RD showed a significantly higher age $(P<0.005)$, brain natriuretic peptide level $(P=0.0001)$, urinary albumin/creatinine excretion ratio in spot urine $(P<0.005)$, pulse wave velocity $(P<0.01)$, left ventricular end-diastolic diameter $(P<0.005)$, and interventricular septal thickness $(P<$ 0.005 ) than the other 973 patients. Candidates for denervation had a significantly lower hemoglobin $(P=0.0001)$, serum albumin $(P<0.001)$, eGFR $(P<0.0005)$, plasma renin activity $(P=0.0001)$, and plasma aldosterone level $(P<0.005)$ than other patients, while their urinary sodium/creatinine ratio was higher, indicating that patients with R-HT appeared to have a high salt intake. Conclusion: Our retrospective clinical survey indicated that only $0.5 \%$ of Japanese hypertensive outpatients (5/999 patients) were candidates for RD. Therefore, establishment of hypertension cohort network will be essential to recruit R-HT patients for RD.
\end{abstract}

\section{Keywords}

Treatment-Resistant Hypertension, Catheter-Based Renal Sympathetic Denervation, Human 


\section{Introduction}

Development of better antihypertensive drugs during the last 40 years has led to marked improvement of outcomes and there is a trend for the mean blood pressure (BP) to decrease in Japan and worldwide. However, the prevalence of hypertension is still increasing in developed countries as the population is aging rapidly. Hypertension remains the single most important lifestyle-related disease, and it is estimated that there are approximately 43 million persons with HT in Japan [1]. Including people with high normal blood pressure, the so-called spare group of HT, the total number could be more than 60 million. Therefore, management of hypertension is essential for preventing cardiovascular disease both in people with hypertension and those with high normal blood pressure, as has been demonstrated by many clinical studies of antihypertensive drugs.

It is sometimes very difficult to manage hypertension, which is known as treatment-resistant hypertension (R-HT), and there may be poor control of both ambulatory and home BP despite using 5 or 6 antihypertensive drugs. Several studies performed in Australia and Europe have demonstrated that catheter-based renal sympathetic denervation (renal denervation) is effective for R-HT [2]-[4], and this treatment will be investigated in Japan in near future. However, the blinded Symplicity HTN-3 trial did not show a significant decrease of BP after renal denervation compared with the sham control [5], and this result has led to controversy [6].

R-HT is often secondary hypertension, and it is important to screen for underlying causes. If it is not secondary hypertension, it is classified as R-HT of unknown etiology, but the prevalence and characteristics of such hypertension have not been determined in Japanese patients. Also, the characteristics of R-HT patients who are indicated for renal denervation have not been clarified. If this were done, it would be easier to identify patients who could benefit from renal denervation and would allow assessment of the need for this procedure in Japan. Therefore, the present study was performed to determine the characteristics of R-TH patients in Japan and the proportion of such patients who are candidates for renal denervation.

\section{Methods}

\subsection{Study Population}

Consecutive outpatients with hypertension $(\mathrm{n}=999)$ attending Fukuoka University Chikushi Hospital (Fukuoka, Japan) from April 2006 to March 2013 were recruited for analysis. Office BP was measured by a standard sphygmomanometer in the sitting position after several minutes sedation and routine physical examination was performed. Patients with a total cholesterol level $>220 \mathrm{mg} / \mathrm{dL}$ ( $5.69 \mathrm{mmol} / \mathrm{L}$ ) or triglycerides $>150 \mathrm{mg} / \mathrm{dL}$ (3.88 $\mathrm{mmol} / \mathrm{L}$ ) or taking lipid-lowering agents were considered to have dyslipidemia. Patients who were being treated for diabetes mellitus or who had symptoms of diabetes and a fasting glucose level $>126 \mathrm{mg} / \mathrm{dl}(7.0 \mathrm{mmol} / \mathrm{L})$ were considered to have diabetes. Otherwise, the results of a $75 \mathrm{~g}$ oral glucose tolerance test were used to diagnose diabetes. Coronary heart disease (CHD) was diagnosed by coronary angiography at the time of enrollment. Patients who were smoking at enrollment were defined as smokers.

Exclusion criteria were stroke, myocardial infarction, other serious cardiovascular complications requiring hospitalization within the previous 6 months, dialysis, acute renal failure, pregnancy and other reasons which made the patient inappropriate for the study in the judgment of the attending physician.

The protocol for this cross-sectional observational study to determine the clinical profile of Japanese R-HT patients was approved by the institutional review board of Fukuoka University Chikushi hospital, and written informed consent was given by all patients before data sampling.

\subsection{Definition of Treatment-Resistant Hypertension}

\subsubsection{R-HT}

The guidelines of the European Society of Cardiology and the American Herat Association define R-HT as systolic BP (SBP) $\geq 140 / 90 \mathrm{mmHg}$ despite lifestyle modification and treatment with 3 or more oral antihypertensive drugs, including a diuretic and 2 or more other antihypertensive drugs at standard or higher doses [7] [8]. In this study, we defined R-HT as an SBP $\geq 140 \mathrm{mmHg}$ despite treatment with 3 oral antihypertensive drugs.

\subsubsection{R-HT Candidates for Renal Denervation}

In the Symplicity HTN-2 study, R-HT patients indicated for renal denervation were defined by a baseline SBP $\geq$ 
$160 \mathrm{mmHg}$ despite treatment with 3 antihypertensive drugs including a diuretic or SBP $\geq 150 \mathrm{mmHg}$ in patients with type 2 diabetes [4].

In the present study, we defined R-HT patients who were candidates for renal denervation as having a baseline SBP $\geq 160 \mathrm{mmHg}$ despite treatment with 3 or more oral antihypertensive drugs including 1 diuretic.

For standard antihypertensive therapy, it is recommended that diuretics should be used in combination with calcium channel blockers (CCB) or renin-angiotensin system inhibitors (RAS-I) such as angiotensin II receptor blockers (ARB) and angiotensin-converting enzyme inhibitors (ACE-I) (Guidelines for Management of Hypertension 2014). According to the results of the ASCOT study and the LIFE study, RAS-I including ARB and ACE-I, CCB, and thiazide diuretics are the commonly used antihypertensive agents [1] [2]. In the present study, the definition of R-HT also required patients to be taking at least 3 classes of antihypertensive drugs (RAS-I, CCB, and diuretics). Because the combination of ARB and ACE-I is not strongly recommended based on the results of the ONTARGET study, combination therapy with drugs from these 2 classes was counted as 1 antihypertensive agent [3].

\subsection{Laboratory Tests}

In addition to the routine laboratory tests, we measured brain natriuretic peptide (BNP). The estimated glomerular filtration rate (eGFR) was calculated using the formula for Japanese patients [4]. To exclude secondary hypertension, a blood sample for endocrine tests was collected from the cubital vein after each patient had rested in the supine position for 30 minutes in the hospital. Various endocrine parameters were measured, including the plasma renin activity (PRA), plasma aldosterone concentration (PAC), plasma adrenaline, plasma noradrenalin, plasma dopamine, serum cortisol, serum thyroid stimulating hormone, and serum free thyroxine. As urine parameters, spot urinary albumin (U-alb), spot urinary sodium (U-Na), spot urinary uric acid, and spot urinary creatinine (U-cre) were determined.

\subsection{Brachial-Ankle Pulse Wave Velocity}

The brachial-ankle pulse wave velocity (baPWV) was measured by using a PWV/ABI apparatus (Omron Colin Co., Ltd.).

\subsection{Transthoracic Echocardiography}

An experienced sonographer obtained all echocardiography data, which was interpreted by an experienced staff echocardiographer. The examinations included M-mode, 2-dimensional, conventional Doppler, and color Doppler echocardiography, with the parameters assessed being the left ventricular end-diastolic diameter (LVDd), interventricular septal thickness (IVST), and ejection fraction (EF).

\subsection{Statistical Analysis}

As items and values to compare, we used gender, smoking history, age, body mass index, white blood cells, hemoglobin $(\mathrm{Hb})$, platelet count, albumin, $\gamma$-GTP, hemoglobin A1c (HbA1c), eGFR, uric acid, high-density lipoprotein, low-density lipoprotein, triglycerides, non-esterified fatty acids, C-reactive protein, BNP, baPWV, LVDd, IVST, EF, urinary examination and endocrine parameters.

Statistical analysis was performed using the SAS software package (version 6.12, SAS Institute Inc., Cary, NC, USA). Results are reported as the mean \pm standard deviation (SD).

Categorical and continuous variables were compared between the groups by chi-square analysis and analysis of variance, respectively, and $\mathrm{P}<0.05$ was considered significant. Univariate analysis and multivariate analysis (logistic regression) were performed to identify independent factors for R-HT.

\section{Results}

We screened 999 outpatients with hypertension and found 65 patients (6.5\%) who had R-HT. Among them, 26 patients (2.6\%) fitted the criteria to be candidates for renal denervation (Table 1). These 26 patients included 12 men and 14 women with a mean age of 74.5 years, SBP of $170.8 \mathrm{mmHg}$, diastolic BP (DBP) of $77.9 \mathrm{mmHg}$, and pulse rate of 70.8/minute. Twenty-five patients were being treated with ARB, 5 with ACE-I, and 4 with 
Table 1. Patients with R-HT who were candidates for renal denervation (renal denervation group).

\begin{tabular}{|c|c|c|c|c|c|c|c|c|c|c|c|}
\hline Patient & Gender & $\begin{array}{l}\text { Age, } \\
\text { Year }\end{array}$ & $\mathrm{DM}$ & Dyslipidemia & $\begin{array}{l}\text { CHD } \\
\text { history }\end{array}$ & Smoking & $\begin{array}{c}\text { SBP } \\
(\mathrm{mmHg})\end{array}$ & $\begin{array}{c}\text { DBP } \\
(\mathrm{mmHg})\end{array}$ & $\begin{array}{c}\mathrm{HR} \\
\text { (bpm) }\end{array}$ & eGFR & $\begin{array}{c}\text { HbA1c } \\
(\%)\end{array}$ \\
\hline 1 & $\mathrm{~F}$ & 66 & $\mathrm{~N}$ & $\mathrm{Y}$ & $\mathrm{N}$ & $\mathrm{N}$ & 168 & 67 & 63 & 63.6 & 5.7 \\
\hline 2 & M & 74 & $\mathrm{~N}$ & $\mathrm{Y}$ & $\mathrm{N}$ & $\mathrm{N}$ & 164 & 70 & 63 & 46.2 & 5.5 \\
\hline 3 & M & 72 & $\mathrm{Y}$ & $\mathrm{Y}$ & $\mathrm{N}$ & $\mathrm{N}$ & 166 & 95 & 78 & 63.8 & 6.1 \\
\hline 4 & F & 92 & $\mathrm{Y}$ & $\mathrm{Y}$ & $\mathrm{N}$ & $\mathrm{N}$ & 162 & 65 & 54 & 68.5 & 6.2 \\
\hline 5 & $\mathrm{~F}$ & 68 & $\mathrm{~N}$ & $\mathrm{~N}$ & $\mathrm{~N}$ & $\mathrm{~N}$ & 179 & 87 & 65 & 91.2 & 5.4 \\
\hline 6 & M & 74 & $\mathrm{~N}$ & $\mathrm{Y}$ & $\mathrm{N}$ & $\mathrm{N}$ & 163 & 67 & 75 & 72.0 & 5 \\
\hline 7 & F & 74 & $\mathrm{~N}$ & $\mathrm{Y}$ & $\mathrm{N}$ & $\mathrm{N}$ & 178 & 82 & 71 & 61.6 & 4.9 \\
\hline 8 & M & 82 & $\mathrm{Y}$ & $\mathrm{N}$ & $\mathrm{N}$ & $\mathrm{N}$ & 170 & 78 & 82 & 54.8 & 5.5 \\
\hline 9 & $\mathrm{~F}$ & 75 & $\mathrm{~N}$ & $\mathrm{~N}$ & AP & $\mathrm{N}$ & 168 & 57 & 70 & 26.6 & 5 \\
\hline 10 & M & 66 & $\mathrm{Y}$ & $\mathrm{Y}$ & $\mathrm{N}$ & $\mathrm{N}$ & 182 & 84 & 68 & 101.9 & 5.8 \\
\hline 11 & M & 82 & $\mathrm{Y}$ & $\mathrm{Y}$ & AP & $\mathrm{N}$ & 160 & 77 & 83 & 28.8 & \\
\hline 12 & $\mathrm{~F}$ & 72 & $\mathrm{~N}$ & $\mathrm{~N}$ & $\mathrm{~N}$ & $\mathrm{~N}$ & 160 & 83 & 93 & 62.1 & 5.4 \\
\hline 13 & M & 73 & $\mathrm{~N}$ & $\mathrm{Y}$ & $\mathrm{N}$ & $\mathrm{N}$ & 166 & 70 & 58 & 63.5 & \\
\hline 14 & $\mathrm{~F}$ & 54 & $\mathrm{~N}$ & $\mathrm{~N}$ & $\mathrm{~N}$ & $\mathrm{~N}$ & 170 & 103 & 89 & 79.8 & 5.4 \\
\hline 15 & $\mathrm{~F}$ & 76 & $\mathrm{~N}$ & $\mathrm{Y}$ & $\mathrm{N}$ & $\mathrm{N}$ & 163 & 71 & 55 & 41.4 & 5.4 \\
\hline 16 & M & 60 & $\mathrm{Y}$ & $\mathrm{Y}$ & $\mathrm{N}$ & $\mathrm{N}$ & 160 & 111 & 105 & 59.9 & 6.1 \\
\hline 17 & $\mathrm{~F}$ & 86 & $\mathrm{Y}$ & $\mathrm{N}$ & $\mathrm{N}$ & $\mathrm{N}$ & 187 & 69 & 64 & 39.9 & 6 \\
\hline 18 & $\mathrm{~F}$ & 77 & $\mathrm{~N}$ & $\mathrm{Y}$ & $\mathrm{N}$ & $\mathrm{N}$ & 181 & 85 & 67 & 60.9 & 5.8 \\
\hline 19 & $\mathrm{~F}$ & 79 & $\mathrm{~N}$ & $\mathrm{~N}$ & $\mathrm{~N}$ & $\mathrm{~N}$ & 161 & 73 & 61 & 87.3 & 5.4 \\
\hline 20 & $\mathrm{~F}$ & 78 & $\mathrm{Y}$ & $\mathrm{Y}$ & $\mathrm{N}$ & $\mathrm{N}$ & 169 & 68 & 75 & 21.6 & \\
\hline 21 & M & 81 & $\mathrm{Y}$ & $\mathrm{N}$ & $\mathrm{N}$ & $\mathrm{N}$ & 163 & 65 & 73 & & 7 \\
\hline 22 & F & 83 & $\mathrm{~N}$ & $\mathrm{~N}$ & $\mathrm{~N}$ & $\mathrm{~N}$ & 196 & 79 & 73 & 59.6 & 5.2 \\
\hline 23 & M & 64 & $\mathrm{Y}$ & $\mathrm{Y}$ & $\mathrm{N}$ & $\mathrm{N}$ & 170 & 75 & 62 & 37.7 & 6.6 \\
\hline 24 & M & 86 & $\mathrm{~N}$ & $\mathrm{~N}$ & $\mathrm{~N}$ & $\mathrm{~N}$ & 192 & 92 & 63 & 9.7 & 4.3 \\
\hline 25 & F & 80 & $\mathrm{~N}$ & $\mathrm{Y}$ & AP & $\mathrm{N}$ & 169 & 75 & 64 & 60.2 & 5.1 \\
\hline 26 & M & 63 & $\mathrm{Y}$ & $\mathrm{Y}$ & $\mathrm{N}$ & $\mathrm{Y}$ & 173 & 78 & 68 & 14.1 & \\
\hline
\end{tabular}

Treatment-resistant hypertension, R-HT for RD; M, male; F, female; DM, diabetes mellitus; Y, Yes; N, No; CHD, coronary heart disease; AP, angina pectoris; SBP, systolic blood pressure; DBP, diastolic blood pressure; HR, heart rate; bpm, beats per minute; eGFR, estimated glomerular filtration rate $\left(\mathrm{ml} / \mathrm{min} / 1.73 \mathrm{~m}^{2}\right)$; HbA1c, hemoglobin A1c.

ARB plus ACE-I (Table 2). All patients were taking CCB, including 3 taking 2 or 3 CCB. All were taking diuretics, including 5 patients using spironolactone. In addition, 8 patients were taking beta-blockers or alphablockers.

Eight patients had chronic kidney disease with an eGFR $<45 \mathrm{ml} / \mathrm{min} / 1.73 \mathrm{~m}^{2}$, accounting for $31 \%$ of the candidates for renal denervation.

The 65 patients with R-HT were divided into 2 groups, a renal denervation group (26 candidates for denervation) and a non-denervation group (the other 973 patients who were not candidates), for comparison by univariate 
Table 2. Medication of R-HT for RD patients.

\begin{tabular}{|c|c|c|c|c|c|c|c|}
\hline Patient & ARB & ACE-I name & CCB name & Diuretic & Sympathetic & Spironolactone & Vasodilator \\
\hline 1 & Candesartan & I midapril & Amlodipine & $\mathrm{Y}$ & $\mathrm{N}$ & $\mathrm{Y}$ & $\mathrm{N}$ \\
\hline 2 & Losartan & & Cilnidipine & $\mathrm{Y}$ & $\mathrm{N}$ & $\mathrm{N}$ & $\mathrm{N}$ \\
\hline 3 & Losartan & & Benidipine & $\mathrm{Y}$ & $\mathrm{N}$ & $\mathrm{N}$ & $\mathrm{N}$ \\
\hline 4 & Valsartan & & Cilnidipine & $\mathrm{Y}$ & $\mathrm{N}$ & $\mathrm{N}$ & $\mathrm{Y}$ \\
\hline 5 & Losartan & & Nifedipine & $\mathrm{Y}$ & $\mathrm{Y}$ & $\mathrm{N}$ & $\mathrm{N}$ \\
\hline 6 & Losartan & I midapril & Cilnidipine & $\mathrm{Y}$ & $\mathrm{N}$ & $\mathrm{N}$ & $\mathrm{N}$ \\
\hline 7 & Valsartan & & Amlodipine & $\mathrm{Y}$ & $\mathrm{N}$ & $\mathrm{N}$ & $\mathrm{N}$ \\
\hline 8 & Valsartan, Losartan & & Azelnidipine, Cilnidipine & $\mathrm{Y}$ & $\mathrm{Y}$ & $\mathrm{Y}$ & $\mathrm{N}$ \\
\hline 9 & Valsartan & & Nifedipine & $\mathrm{Y}$ & $\mathrm{Y}$ & $\mathrm{N}$ & $\mathrm{Y}$ \\
\hline 10 & Losartan & & Cilnidipine & $\mathrm{Y}$ & $\mathrm{N}$ & $\mathrm{N}$ & $\mathrm{N}$ \\
\hline 11 & I rbesartan, Losartan & & Diltiazem & $\mathrm{Y}$ & $\mathrm{N}$ & $\mathrm{N}$ & $\mathrm{N}$ \\
\hline 12 & Telmisartan & & Benidipine & $\mathrm{Y}$ & $\mathrm{N}$ & $\mathrm{N}$ & $\mathrm{N}$ \\
\hline 13 & Valsartan & & Amlodipine & $\mathrm{Y}$ & $\mathrm{N}$ & $\mathrm{N}$ & $\mathrm{N}$ \\
\hline 14 & Valsartan & I midapril & Amlodipine & $\mathrm{Y}$ & $\mathrm{N}$ & $\mathrm{Y}$ & $\mathrm{N}$ \\
\hline 15 & Olmesartan & Lisinopril & Nifedipine & $\mathrm{Y}$ & $\mathrm{N}$ & $\mathrm{N}$ & $\mathrm{N}$ \\
\hline 16 & Losartan & & Nifedipine & $\mathrm{Y}$ & $\mathrm{N}$ & $\mathrm{N}$ & $\mathrm{N}$ \\
\hline 17 & Olmesartan & & Azelnidipine & $\mathrm{Y}$ & $\mathrm{N}$ & $\mathrm{Y}$ & $\mathrm{N}$ \\
\hline 18 & Losartan & & Amlodipine & $\mathrm{Y}$ & $\mathrm{Y}$ & $\mathrm{N}$ & $\mathrm{N}$ \\
\hline 19 & Valsartan & & Cilnidipine & $\mathrm{Y}$ & $\mathrm{N}$ & $\mathrm{N}$ & $\mathrm{N}$ \\
\hline 20 & Olmesartan & & $\begin{array}{l}\text { Cilnidipine, Azelnidipine, } \\
\text { Nifedipine }\end{array}$ & $\mathrm{Y}$ & $\mathrm{Y}$ & $\mathrm{N}$ & $\mathrm{N}$ \\
\hline 21 & Valsartan & & Nifedipine & $\mathrm{Y}$ & $\mathrm{N}$ & $\mathrm{N}$ & $\mathrm{Y}$ \\
\hline 22 & Candesartan & & Nifedipine & $\mathrm{Y}$ & $\mathrm{N}$ & $\mathrm{N}$ & $\mathrm{N}$ \\
\hline 23 & Candesartan & & Amlodipine, Nifedipine & $\mathrm{Y}$ & $\mathrm{Y}$ & $\mathrm{Y}$ & $\mathrm{N}$ \\
\hline 24 & I rbesartan & & Diltiazem & $\mathrm{Y}$ & $\mathrm{N}$ & $\mathrm{N}$ & $\mathrm{Y}$ \\
\hline 25 & Olmesartan & & Diltiazem & $\mathrm{Y}$ & $\mathrm{Y}$ & $\mathrm{N}$ & $\mathrm{Y}$ \\
\hline 26 & & Enalapril & Nifedipine & $\mathrm{Y}$ & $\mathrm{Y}$ & $\mathrm{N}$ & $\mathrm{N}$ \\
\hline
\end{tabular}

ARB, angiotensin II receptor blocker; ACE-I, angiotensin converting enzyme inhibitor; CCB, calcium channel blocker; For other abbreviations, see Table 1.

analysis (Table 3). The age, BNP, U-alb/U-cre ratio, baPWV, LVDd, and IVST were significantly higher/larger in the renal denervation group compared with the non-denervation group, while the levels of $\mathrm{Hb}$, serum albumin, eGFR, PRA, PAC, and thyroxine were significantly lower. The U-Na/U-cre ratio tended to be higher in the renal denervation group. Complete data on HbA1c, eGFR, and BNP were not available for some patients, and they were excluded from the relevant univariate analyses.

In addition, we investigated independent factors related to patients being indicated for renal denervation by multivariate analysis, but we could not identify any significant factors. 
Table 3. Comparison of the renal denervation (RD) group with the other patients (Non-RD group).

\begin{tabular}{|c|c|c|c|c|c|}
\hline & \multicolumn{2}{|c|}{ RD group $(\mathrm{N}=26)$} & \multicolumn{2}{|c|}{ non-RD group $(\mathrm{N}=973)$} & \multirow[b]{2}{*}{$\mathrm{p}$ value } \\
\hline & Frequencyy & Ratio (\%) & Frequency & Ratio (\%) & \\
\hline Gender (Male) & 12 & 46.2 & 512 & 52.7 & NS \\
\hline \multirow[t]{2}{*}{ Smoking } & 1 & 3.9 & 156 & 16.0 & NS \\
\hline & $\mathrm{n}$ & Mean \pm S.D & $\mathrm{n}$ & Mean \pm S.D & $\mathrm{p}$ value \\
\hline Age, years & 26 & $74.5 \pm 8.8$ & 973 & $66.3 \pm 13.5$ & $<0.005$ \\
\hline BMI, kg/m² & 26 & $24.5 \pm 3.1$ & 968 & $23.4 \pm 3.5$ & NS \\
\hline WBC, $10^{3} / \mu \mathrm{L}$ & 26 & $5.77 \pm 1.37$ & 969 & $5.50 \pm 1.81$ & NS \\
\hline $\mathrm{Hb}, \mathrm{g} / \mathrm{dl}$ & 26 & $12.2 \pm 2.2$ & 969 & $13.4 \pm 1.7$ & 0.0001 \\
\hline $\mathrm{PLT}, 10^{4} / \mu \mathrm{L}$ & 26 & $20.1 \pm 8.0$ & 969 & $20.1 \pm 5.5$ & NS \\
\hline Alb, g/dL & 24 & $4.0 \pm 0.7$ & 916 & $4.2 \pm 0.4$ & $<0.001$ \\
\hline$\gamma$-GTP, U/L & 26 & $26.9 \pm 13.1$ & 958 & $40.1 \pm 71.4$ & NS \\
\hline HbA1c, \% & 22 & $5.6 \pm 0.6$ & 913 & $5.6 \pm 0.8$ & NS \\
\hline eGFR, $\mathrm{ml} / \mathrm{min} / 1.73 \mathrm{~m}^{2}$ & 25 & $55.1 \pm 23.4$ & 966 & $66.2 \pm 19.1$ & $<0.0005$ \\
\hline $\mathrm{UA}, \mathrm{mg} / \mathrm{dL}$ & 25 & $5.7 \pm 1.6$ & 959 & $5.4 \pm 1.3$ & NS \\
\hline $\mathrm{HDL}, \mathrm{mg} / \mathrm{dL}$ & 25 & $65.5 \pm 19.6$ & 958 & $59.6 \pm 14.5$ & 0.09 \\
\hline LDL, mg/dL & 25 & $104.1 \pm 22.9$ & 956 & $112.6 \pm 28.1$ & NS \\
\hline $\mathrm{TG}, \mathrm{mg} / \mathrm{dL}$ & 25 & $111.8 \pm 60.6$ & 957 & $119.3 \pm 75.2$ & NS \\
\hline $\mathrm{NEFA}, \mu \mathrm{Eq} / \mathrm{L}$ & 20 & $565.6 \pm 180.6$ & 839 & $499.0 \pm 234.7$ & 0.095 \\
\hline $\mathrm{CRP}, \mathrm{mg} / \mathrm{dL}$ & 24 & $0.1 \pm 0.1$ & 953 & $0.3 \pm 1.2$ & NS \\
\hline BNP, pg/mL & 23 & $134.1 \pm 254.6$ & 861 & $47.9 \pm 126.8$ & 0.0001 \\
\hline baPWV, cm/sec & 22 & $2079 \pm 707$ & 798 & $1790 \pm 459$ & $<0.01$ \\
\hline LVDd, mm & 24 & $50.7 \pm 5.6$ & 812 & $47.8 \pm 4.8$ & $<0.005$ \\
\hline IVST, mm & 24 & $9.3 \pm 1.7$ & 813 & $8.4 \pm 1.4$ & $<0.005$ \\
\hline $\mathrm{EF}, \%$ & 24 & $66.8 \pm 7.5$ & 808 & $66.7 \pm 7.9$ & NS \\
\hline Spot U-alb/U-cre ratio* & 24 & $417.9 \pm 1072.9$ & 902 & $78.1 \pm 421.7$ & $<0.005$ \\
\hline Spot U-UA/U-cre ratio ${ }^{*}$ & 23 & $0.5 \pm 0.2$ & 878 & $0.5 \pm 0.2$ & NS \\
\hline Spot U-Na/U-cre ratio ${ }^{* *}$ & 22 & $2.1 \pm 1.4$ & 860 & $1.7 \pm 1.2$ & 0.07 \\
\hline PRA, ng/ml/h & 10 & $0.9 \pm 0.8$ & 292 & $1.5 \pm 2.2$ & 0.0001 \\
\hline PAC, pg/mL & 10 & $38.2 \pm 17.8$ & 293 & $70.0 \pm 61.0$ & $<0.005$ \\
\hline Adrenaline, pg/mL & 9 & $42.1 \pm 26.9$ & 287 & $37.2 \pm 29.4$ & NS \\
\hline Noradrenalin, pg/mL & 9 & $578.9 \pm 551.0$ & 287 & $384.8 \pm 186.4$ & NS \\
\hline Dopamine, $\mathrm{pg} / \mathrm{mL}$ & 9 & $18.2 \pm 14.5$ & 287 & $15.7 \pm 48.7$ & NS \\
\hline Cortisol, $\mu \mathrm{g} / \mathrm{dL}$ & 9 & $9.3 \pm 3.4$ & 286 & $10.1 \pm 4.9$ & NS \\
\hline $\mathrm{TSH}, \mu \mathrm{IU} / \mathrm{mL}$ & 8 & $58.9 \pm 161.7$ & 321 & $2.1 \pm 2.8$ & $<0.05$ \\
\hline FT4, ng//dL & 8 & $1.1 \pm 0.4$ & 321 & $1.2 \pm 0.2$ & $<0.001$ \\
\hline
\end{tabular}

${ }^{*}(\mathrm{mg} / \mathrm{dL}) /(\mathrm{mg} / \mathrm{dL}){ }^{* *}(\mathrm{mmol} / \mathrm{L}) /(\mathrm{mg} / \mathrm{dL})$; BMI, body mass index; WBC, White blood cells; Hb, hemoglobin; Plt, platelet count; alb, albumin; UA, uric acid; HDL, high-density lipoprotein; LDL, low-density lipoprotein; TG, triglycerides; NEFA, non-esterified fatty acids; CRP, C-reactive protein; BNP, brain natriuretic peptide; baPWV, brachial-ankle pulse wave velocity; LVDd, left ventricular end-diastolic diameter; IVST, interventricular septal thickness; EF, ejection fraction; U, urinary; cre, creatinine; Na, sodium; PRA, plasma renin activity; PAC, plasma aldosterone concentration; TSH, thyroid stimulating hormone; FT4, free thyroxine; For other abbreviations, see Table 1. 


\section{Discussion}

The major findings of the present study were as follows:

1) Among 999 outpatients with hypertension, $6.5 \%(n=65)$ had R-HT and $2.6 \%(n=26)$ were candidates for renal sympathetic denervation (renal denervation group).

2) Compared with the 973 patients who were not indicated for denervation (non-denervation group), the renal denervation group was older, had a higher BNP, U-alb/U-cre ratio, U-Na/U-cre ratio, and baPWV, and had a higher LVDd and greater IVST on echocardiography. In addition, the renal denervation group had lower levels of Hb, albumin, eGFR, PRA, PAC, and thyroxine compared with the non-denervation group.

\subsection{Characteristics of the Renal Denervation Group}

According to the National Health and Nutrition Examination Survey conducted in the United States, 8.9\% of adult patients with hypertension have R-HT and $12.8 \%$ of patients taking antihypertensive drugs have R-HT [5]. Compared with the United States, the prevalence of R-HT was lower (6.5\%) in Japanese patients according to this study. Since it is known that salt intake is substantially higher among Japanese people than western populations [6], it is probable that diuretics are effective and reduce the prevalence of R-HT in Japan. Indeed, the lower PRA and PAC of our renal denervation group are characteristic of excessive salt intake [7]. The U-Na/U-cre ratio is a simple marker of salt intake used in clinical practice [8], and this ratio tended to be higher in our renal denervation group. Thus, it is likely that many patients in the renal denervation group had excessive salt intake.

Although there was a significant difference of thyroid hormone levels between the renal denervation group and the non-denervation group, 1 patient (No. 24) with thyroid dysfunction in the renal denervation group seemed to influence this result since the significant difference disappeared when data were analyzed after excluding the data of this patient. There were no significant differences of catecholamines between the 2 groups. In the renal denervation group, eGFR was significantly lower than in the non-denervation group and chronic kidney disease was more frequent (50\%: 13/26 patients) than in the non-denervation group with (34\%: 332/973 patients).

The high frequency of albuminuria and hypoalbuminemia in the renal denervation group may have been secondary to chronic kidney disease. The renal denervation group had a significantly lower $\mathrm{Hb}$ than the nondenervation group and showed a tendency for anemia, which could be related to lower erythropoietin production due to chronic kidney disease or hemodilution due to impaired excretion water resulting from renal dysfunction.

In the renal denervation group, patients tended to have left ventricular hypertrophy based on the echocardiography findings and BNP was also high. Thus, there was evidence of progressive cardiac remodeling associated with hypertension in this group.

Patients in the renal denervation group also showed a high baPWV, indicating advanced arterial stiffness. Therefore, despite treatment with multiple antihypertensive drugs, R-HT patients who were candidates for renal denervation had evidence of multiple organ impairment, a finding consistent with previous reports.

\subsection{Investigating Candidates for Renal Denervation}

A clinical trial of renal denervation was started in Japan, but it was halted in December 2014 due to difficulty in recruiting patients. One of the reasons for this outcome is that the indications for renal denervation are extremely limited [9]. In investigations of renal denervation, it is necessary to set limits on blood pressure and renal function, as well as excluding patients with secondary hypertension and masked-hypertension [10]. Because patients who require 3 antihypertensive drugs tend to have nephrosclerosis and renal dysfunction, many of them are unsuitable for renal denervation.

In the Symplicity HTN-3 study, patients between the ages of 18 and 80 were indicated for renal denervation [11]. In our study, 7 out of 26 candidate patients were at least 81 years old and thus were excluded. Another 3 patients (Nos. 18, 19, and 25) had reached the age of 81 at the time of performing this analysis, so they were also excluded, resulting in 10 patients (38\%) being excluded because of their age.

Next, patients with chronic kidney disease and an eGFR $<45 \mathrm{ml} / \mathrm{min} / 1.73 \mathrm{~m}^{2}$ were excluded based on the published indications [11]. In this study, 8 of the candidates for renal denervation (31\%) had an eGFR $<45$ $\mathrm{ml} / \mathrm{min} / 1.73 \mathrm{~m}^{2}$.

Taken together, the criteria for age and renal function excluded 15 of our candidate patients (58\%) from renal 
denervation, so these two factors seem to have a substantial influence on the number of patients who can actually undergo denervation.

The details of the remaining 11 patients are shown in Table 4. Before performing renal sympathetic denervation, it is necessary to exclude secondary causes of hypertension, such as renovascular hypertension, endocrine diseases including primary aldosteronism, Cushing syndrome, pheochromocytoma, hyperthyroidism, sleep apnea syndrome, and drug-induced hypertension [12].

In screening for primary aldosteronism, a PAC/PRA ratio >200 is usually employed [7] [13]. Two patients (Nos. 5 and 6) had a PAC/PRA ratio >200 and were suspected to have primary aldosteronism, so they were excluded from the renal denervation group for further assessment.

Another patient (No. 16) had a very high renin level that suggested renovascular hypertension and was also excluded (Figure 1).

There were no patients with suspected pheochromocytoma and no patients with pseudoaldosteronism caused by excessive consumption of licorice.

Since BP can be increased by salt intake, it is important to try lifestyle modification including control of salt intake before performing renal denervation. We evaluated salt intake from the U-Na and U-cre levels [8] [14], and identified 3 patients (Nos. 1, 12 and 13) who apparently had excessive salt intake. It was considered likely that salt restriction would improve the BP of these patients.

Finally, as shown in Figure 1, 5 out of 999 consecutive patients with hypertension were indicated for renal denervation, representing $0.5 \%$ of the subjects in our study. Of course, it is not clear that all of these patients would give consent to renal denervation and we also did not determine whether their renal artery anatomy was suitable, which would require further examination by renal arteriography, computed tomography, and ultrasound.

Thus, our study found very few hypertensive patients in whom renal denervation was indicated. In a similar study of 1756 hypertensive patients, only 14 patients (0.8\%) were indicated for renal denervation [15], which is comparable to our rate of $0.5 \%$. It has been reported that there are approximately 43 million hypertensive patients in Japan [16]. Since the prevalence of R-HT was $2.6 \%$ in our study, it can be estimated that there are approximately 1.12 million patients with R-HT in Japan, suggesting that renal denervation may be indicated in around 220,000 patients because the rate was $0.5 \%$ in the present study. Clinical trials of renal denervation in Japan would seem to have a problem with recruiting patients, but we first need to identify more patients with R-HT by screening and education. For example, establishing a large clinical cohort of hypertensive patients like

Table 4. Endocrine findings in R-HT candidates for renal denervation.

\begin{tabular}{cccccccccc}
\hline Patient & Gender & Age & BMI & $\begin{array}{c}\text { PRA } \\
(\mathrm{ng} / \mathrm{ml} / \mathrm{h})\end{array}$ & $\begin{array}{c}\mathrm{PAC} \\
(\mathrm{pg} / \mathrm{ml})\end{array}$ & ARR & $\begin{array}{c}\text { U-Na } \\
(\mathrm{mEq} / \mathrm{L})\end{array}$ & $\begin{array}{c}\text { U-Cre } \\
(\mathrm{mg} / \mathrm{dL})\end{array}$ & $\begin{array}{c}\text { Salt intake } \\
(\mathrm{g} / \mathrm{day})\end{array}$ \\
\hline 1 & $\mathrm{~F}$ & 66 & 32.8 & 0.4 & 66.3 & 165.8 & 76 & 10.8 & 16.3 \\
2 & $\mathrm{M}$ & 74 & 27.1 & 0.3 & 36.2 & 120.7 & 92 & 86.6 & 8.9 \\
3 & $\mathrm{M}$ & 72 & 24.3 & 0.4 & 39.7 & 99.3 & 106 & 167.2 & 7.6 \\
5 & $\mathrm{~F}$ & 68 & 21.1 & 0.2 & 104 & 520.0 & 49 & 50.6 & 6.9 \\
6 & M & 74 & 25.7 & 0.2 & 71.3 & 356.5 & 166 & 132.6 & 9.1 \\
7 & F & 74 & 20.0 & 0.7 & 65.5 & 93.6 & 158 & 73.4 & 9.5 \\
10 & M & 66 & 22.8 & 2.5 & 51.7 & 20.7 & 87 & 56.8 & 10 \\
12 & F & 72 & 22.4 & 1.5 & 38.9 & 25.9 & 121 & 17.3 & 16.7 \\
13 & M & 73 & 29.2 & 0.5 & 42.6 & 85.2 & 172 & 96.9 & 12.5 \\
14 & F & 54 & 23.1 & 2.2 & 118 & 53.6 & 87 & 290.4 & 4.7 \\
16 & M & 60 & 22.9 & $>20$ & 37 & $<1.85$ & 97 & 608 & $<4.8$
\end{tabular}

ARR, PAC/PRA ratio; For other abbreviations, see Table 1 and Table 3. 


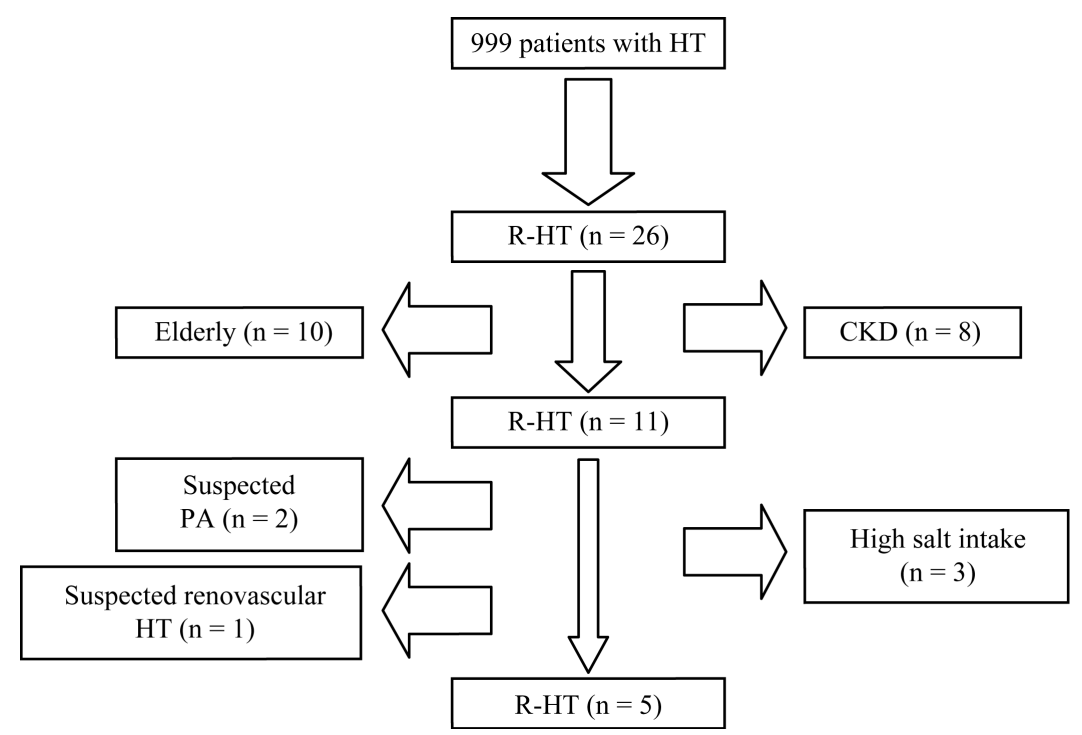

Among 999 patients with hypertension (HT), there were 26 patients with resistant hypertension (R-HT) who were candidates for renal denervation. In this group, 10 patients were too old (>81 years) and 8 had chronic kidney disease (CKD). Because these patients overlapped, only 15 were excluded due to old age and CKD. The remaining 11 patients included 2 with suspected primary aldosteronism (PA), 1 with renovascular HT, and 3 with high salt intake. Finally, only 5 patients remained as candidates for renal denervation.

Figure 1. Selection of patients for renal denervation.

those at hypertension centers in Germany may help to identify R-HT patients by screening. Thus, we realized that not only for renal deneravation but for treatment of R-HT establishment of a large cohort including mild to severe hypertensive out patients was primary requirement.

It has been reported that renal denervation is more effective in patients with a higher BP before the procedure [17], suggesting that our patients No. 2 and No. 6 might be good candidates.

It was reported that Chinese are more sensitive than Caucasians to the effects of the beta-blocker propranolol on the pulse rate and BP [18]. Because Asians appear to be more sensitive to beta-blockers, renal denervation may be more effective for Asian patients with R-HT, and patients who have tachycardia like our No. 16 could be good candidates.

One cause of difficulty in controlling BP is poor adherence to medication, while good adherence can significantly improve control and reduce the risk of cardiovascular disease [19]-[21]. If a patient has to take multiple drugs, adherence is more likely to decrease, while reducing the frequency of medication or employing combination drugs can improve both adherence and BP [22] [23]. Thus, combining antihypertensive therapy and renal denervation may improve the prognosis of selected patients with hypertension.

\subsection{Clinical Implications}

After we started screening for renal denervation candidates at our hospital, we found more patients with secondary hypertension than before including cases of primary aldosteronism, renovascular hypertension, and pseudoaldosteronism due to licorice. This has led to an increase of adrenal venous sampling, renal arteriography, and arterioplasty at our hospital due to more comprehensive treatment of secondary hypertension. By results of this study, we realized the importance of diagnosis of secondary hypertension, intensive care by antihypertensive drugs and sodium restriction treatment.

Renal denervation will be recognized as a cost-effective intervention for hypertension if it improves life expectancy and other variables in outcome studies. In terms of surrogate endpoints, there is already evidence that renal denervation decreases arrhythmias such as atrial fibrillation, proteinuria, diabetes, sleep apnea syndrome, congestive heart failure, arteriosclerosis, and left ventricular remodeling [24]-[31]. More recently, it was reported that renal denervation improves depression and the quality of life [32] [33], while targeting suitable patients may contribute to reduction of medical expenses. 


\section{Limitations}

Since this was a retrospective cross-sectional observational study, the findings are not conclusive. In addition, we did not employ ambulatory BP monitoring and only assessed the office BP, so it would be desirable to evaluate home BP and nocturnal BP in further studies. We also did not distinguish masked R-HT and sleep apnea syndrome from R-HT. Furthermore, we did not analyze adherence to medication or the doses of antihypertensive drugs used by the patients. Finally, complete data were not available for some patients and multivariate analysis failed to identify factors with an independent influence on R-HT.

\section{Conclusion}

In this retrospective analysis, we found that there were very few patients with R-HT among consecutive new outpatients with hypertension, and that renal denervation was indicated for only $0.5 \%$ of new hypertensive patients. Patients in whom renal denervation was indicated often had cardiomegaly and arteriosclerosis, and salt sensitivity was sometimes suspected as the underlying cause. Because many of the patients who may benefit from renal denervation have not been identified, it seems important to establish a cohort study that facilitates assessment of patients with R-HT.

\section{Acknowledgements}

We appreciate Mrs. Harumi Arimura for her excellent technical assistance.

\section{Conflict of Interests}

The authors declare that there is no conflict of interests regarding the publication of this paper.

\section{References}

[1] Dahlof, B., Sever, P.S., Poulter, N.R., Wedel, H., Beevers, D.G., Caulfield, M., Collins, R., Kjeldsen, S.E., Kristinsson, A., McInnes, G.T., Mehlsen, J., Nieminen, M., O’Brien, E. and Ostergren, J. (2005) Prevention of Cardiovascular Events with an Antihypertensive Regimen of Amlodipine Adding Perindopril as Required versus Atenolol Adding Bendroflumethiazide as Required, in the Anglo-Scandinavian Cardiac Outcomes Trial-Blood Pressure Lowering Arm (ASCOT-BPLA): A Multicentre Randomised Controlled Trial. The Lancet, 366, 895-906. http://dx.doi.org/10.1016/S0140-6736(05)67185-1

[2] Dahlof, B., Devereux, R.B., Kjeldsen, S.E., Julius, S., Beevers, G., de Faire, U., Fyhrquist, F., Ibsen, H., Kristiansson, K., Lederballe-Pedersen, O., Lindholm, L.H., Nieminen, M.S., Omvik, P., Oparil, S. and Wedel, H. (2002) Cardiovascular Morbidity and Mortality in the Losartan Intervention for Endpoint Reduction in Hypertension Study (LIFE): A Randomised Trial against Atenolol. The Lancet, 359, 995-1003. http://dx.doi.org/10.1016/S0140-6736(02)08089-3

[3] Yusuf, S., Teo, K.K., Pogue, J., Dyal, L., Copland, I., Schumacher, H., Dagenais, G., Sleight, P. and Anderson, C. (2008) Telmisartan, Ramipril, or Both in Patients at High Risk for Vascular Events. The New England Journal of Medicine, 358, 1547-1559. http://dx.doi.org/10.1056/NEJMoa0801317

[4] Matsuo, S., Imai, E., Horio, M., Yasuda, Y., Tomita, K., Nitta, K., Yamagata, K., Tomino, Y., Yokoyama, H. and Hishida, A. (2009) Revised Equations for Estimated GFR from Serum Creatinine in Japan. American Journal of Kidney Diseases, 53, 982-992. http://dx.doi.org/10.1053/j.ajkd.2008.12.034

[5] Persell, S.D. (2011) Prevalence of Resistant Hypertension in the United States, 2003-2008. Hypertension, 57, 10761080. http://dx.doi.org/10.1161/HYPERTENSIONAHA.111.170308

[6] The INTERSALT Co-Operative Research Group (1989) Appendix Tables. Centre-Specific Results by Age and Sex. Journal of Human Hypertension, 3, 331-407.

[7] Funder, J.W., Carey, R.M., Fardella, C., Gomez-Sanchez, C.E., Mantero, F., Stowasser, M., Young Jr., W.F. and Montori, V.M. (2008) Case Detection, Diagnosis, and Treatment of Patients with Primary Aldosteronism: An Endocrine Society Clinical Practice Guideline. The Journal of Clinical Endocrinology \& Metabolism, 93, 3266-3281. http://dx.doi.org/10.1210/jc.2008-0104

[8] Kawano, Y., Tsuchihashi, T., Matsuura, H., Ando, K., Fujita, T. and Ueshima, H. (2007) Report of the Working Group for Dietary Salt Reduction of the Japanese Society of Hypertension: (2) Assessment of Salt Intake in the Management of Hypertension. Hypertension Research, 30, 887-893. http://dx.doi.org/10.1291/hypres.30.887

[9] Schlaich, M.P., Schmieder, R.E., Bakris, G., Blankestijn, P.J., Bohm, M., Campese, V.M., Francis, D.P., Grassi, G., Hering, D., Katholi, R., Kjeldsen, S., Krum, H., Mahfoud, F., Mancia, G., Messerli, F.H., Narkiewicz, K., Parati, G., 
Rocha-Singh, K.J., Ruilope, L.M., Rump, L.C., Sica, D.A., Sobotka, P.A., Tsioufis, C., Vonend, O., Weber, M.A., Williams, B., Zeller, T. and Esler, M.D. (2013) International Expert Consensus Statement: Percutaneous Transluminal Renal Denervation for the Treatment of Resistant Hypertension. Journal of the American College of Cardiology, 62, 2031-2045. http://dx.doi.org/10.1016/j.jacc.2013.08.1616

[10] Esler, M.D., Krum, H., Sobotka, P.A., Schlaich, M.P., Schmieder, R.E. and Bohm, M. (2010) Renal Sympathetic Denervation in Patients with Treatment-Resistant Hypertension (The Symplicity HTN-2 Trial): A Randomised Controlled Trial. The Lancet, 376, 1903-1909. http://dx.doi.org/10.1016/S0140-6736(10)62039-9

[11] Kandzari, D.E., Bhatt, D.L., Sobotka, P.A., O’Neill, W.W., Esler, M., Flack, J.M., Katzen, B.T., Leon, M.B., Massaro, J.M., Negoita, M., Oparil, S., Rocha-Singh, K., Straley, C., Townsend, R.R. and Bakris, G. (2012) Catheter-Based Renal Denervation for Resistant Hypertension: Rationale and Design of the SYMPLICITY HTN-3 Trial. Clinical Cardiology, 35, 528-535. http://dx.doi.org/10.1002/clc.22008

[12] Calhoun, D.A., Jones, D., Textor, S., Goff, D.C., Murphy, T.P., Toto, R.D., White, A., Cushman, W.C., White, W., Sica, D., Ferdinand, K., Giles, T.D., Falkner, B. and Carey, R.M. (2008) Resistant Hypertension: Diagnosis, Evaluation, and Treatment. A Scientific Statement from the American Heart Association Professional Education Committee of the Council for High Blood Pressure Research. Hypertension, 51, 1403-1419. http://dx.doi.org/10.1161/HYPERTENSIONAHA.108.189141

[13] Nishizaka, M.K., Pratt-Ubunama, M., Zaman, M.A., Cofield, S. and Calhoun, D.A. (2005) Validity of Plasma Aldosterone-to-Renin Activity Ratio in African American and White Subjects with Resistant Hypertension. American Journal of Hypertension, 18, 805-812. http://dx.doi.org/10.1016/j.amjhyper.2005.01.002

[14] Tanaka, T., Okamura, T., Miura, K., Kadowaki, T., Ueshima, H., Nakagawa, H. and Hashimoto, T. (2002) A Simple Method to Estimate Populational 24-h Urinary Sodium and Potassium Excretion Using a Casual Urine Specimen. Journal of Human Hypertension, 16, 97-103. http://dx.doi.org/10.1038/sj.jhh.1001307

[15] Hayek, S.S., Abdou, M.H., Demoss, B.D., Legaspi, J.M., Veledar, E., Deka, A., Krishnan, S.K., Wilmot, K.A., Patel, A.D., Kumar, V.R. and Devireddy, C.M. (2013) Prevalence of Resistant Hypertension and Eligibility for CatheterBased Renal Denervation in Hypertensive Outpatients. American Journal of Hypertension, 26, 1452-1458. http://dx.doi.org/10.1093/ajh/hpt132

[16] Miura, K., Nagai, M. and Ohkubo, T. (2013) Epidemiology of Hypertension in Japan: Where Are We Now? Circulation Journal, 77, 2226-2231. http://dx.doi.org/10.1253/circj.CJ-13-0847

[17] Prochnau, D., Heymel, S., Gobel, B., Figulla, H.R. and Surber, R. (2013) Resistant Hypertension: Multivariate Predictors of Blood Pressure Response to Renal Denervation. International Journal of Cardiology, 168, 3130-3132. http://dx.doi.org/10.1016/j.ijcard.2013.04.035

[18] Zhou, H.H., Koshakji, R.P., Silberstein, D.J., Wilkinson, G.R. and Wood, A.J. (1989) Altered Sensitivity to and Clearance of Propranolol in Men of Chinese Descent as Compared with American Whites. New England Journal of Medicine, 320, 565-570. http://dx.doi.org/10.1056/NEJM198903023200905

[19] Calhoun, D.A., Jones, D., Textor, S., Goff, D.C., Murphy, T.P., Toto, R.D., White, A., Cushman, W.C., White, W., Sica, D., Ferdinand, K., Giles, T.D., Falkner, B. and Carey, R.M. (2008) Resistant Hypertension: Diagnosis, Evaluation, and Treatment: A Scientific Statement from the American Heart Association Professional Education Committee of the Council for High Blood Pressure Research. Circulation, 117, e510-e526. http://dx.doi.org/10.1161/CIRCULATIONAHA.108.189141

[20] Bramley, T.J., Gerbino, P.P., Nightengale, B.S. and Frech-Tamas, F. (2006) Relationship of Blood Pressure Control to Adherence with Antihypertensive Monotherapy in 13 Managed Care Organizations. Journal of Managed Care Pharmacy, 12, 239-245.

[21] Corrao, G., Parodi, A., Nicotra, F., Zambon, A., Merlino, L., Cesana, G. and Mancia, G. (2011) Better Compliance to Antihypertensive Medications Reduces Cardiovascular Risk. Journal of Hypertension, 29, 610-618. http://dx.doi.org/10.1097/HJH.0b013e328342ca97

[22] Claxton, A.J., Cramer, J. and Pierce, C. (2001) A Systematic Review of the Associations between Dose Regimens and Medication Compliance. Clinical Therapeutics, 23, 1296-1310. http://dx.doi.org/10.1016/S0149-2918(01)80109-0

[23] Thom, S., Poulter, N., Field, J., Patel, A., Prabhakaran, D., Stanton, A., Grobbee, D.E., Bots, M.L., Reddy, K.S., Cidambi, R., Bompoint, S., Billot, L. and Rodgers, A. (2013) Effects of a Fixed-Dose Combination Strategy on Adherence and Risk Factors in Patients with or at High Risk of CVD: The UMPIRE Randomized Clinical Trial. JAMA, 310, 918-929. http://dx.doi.org/10.1001/jama.2013.277064

[24] Dorenkamp, M., Bonaventura, K., Leber, A.W., Boldt, J., Sohns, C., Boldt, L.H., Haverkamp, W., Frei, U. and Roser, M. (2013) Potential Lifetime Cost-Effectiveness of Catheter-Based Renal Sympathetic Denervation in Patients with Resistant Hypertension. European Heart Journal, 34, 451-461. http://dx.doi.org/10.1093/eurheartj/ehs355

[25] Geisler, B.P., Egan, B.M., Cohen, J.T., Garner, A.M., Akehurst, R.L., Esler, M.D. and Pietzsch, J.B. (2012) CostEffectiveness and Clinical Effectiveness of Catheter-Based Renal Denervation for Resistant Hypertension. Journal of 
the American College of Cardiology, 60, 1271-1277. http://dx.doi.org/10.1016/j.jacc.2012.07.029

[26] Pokushalov, E., Romanov, A., Corbucci, G., Artyomenko, S., Baranova, V., Turov, A., Shirokova, N., Karaskov, A., Mittal, S. and Steinberg, J.S. (2012) A Randomized Comparison of Pulmonary Vein Isolation with versus without Concomitant Renal Artery Denervation in Patients with Refractory Symptomatic Atrial Fibrillation and Resistant Hypertension. Journal of the American College of Cardiology, 60, 1163-1170. http://dx.doi.org/10.1016/j.jacc.2012.05.036

[27] Mahfoud, F., Cremers, B., Janker, J., Link, B., Vonend, O., Ukena, C., Linz, D., Schmieder, R., Rump, L.C., Kindermann, I., Sobotka, P.A., Krum, H., Scheller, B., Schlaich, M., Laufs, U. and Bohm, M. (2012) Renal Hemodynamics and Renal Function after Catheter-Based Renal Sympathetic Denervation in Patients with Resistant Hypertension. Hypertension, 60, 419-424. http://dx.doi.org/10.1161/HYPERTENSIONAHA.112.193870

[28] Mahfoud, F., Schlaich, M., Kindermann, I., Ukena, C., Cremers, B., Brandt, M.C., Hoppe, U.C., Vonend, O., Rump, L.C., Sobotka, P.A., Krum, H., Esler, M. and Bohm, M. (2011) Effect of Renal Sympathetic Denervation on Glucose Metabolism in Patients with Resistant Hypertension: A Pilot Study. Circulation, 123, 1940-1946. http://dx.doi.org/10.1161/CIRCULATIONAHA.110.991869

[29] Witkowski, A., Prejbisz, A., Florczak, E., Kadziela, J., Sliwinski, P., Bielen, P., Michalowska, I., Kabat, M., Warchol, E., Januszewicz, M., Narkiewicz, K., Somers, V.K., Sobotka, P.A. and Januszewicz, A. (2011) Effects of Renal Sympathetic Denervation on Blood Pressure, Sleep Apnea Course, and Glycemic Control in Patients with Resistant Hypertension and Sleep Apnea. Hypertension, 58, 559-565. http://dx.doi.org/10.1161/HYPERTENSIONAHA.111.173799

[30] Hering, D., Lambert, E.A., Marusic, P., Ika-Sari, C., Walton, A.S., Krum, H., Sobotka, P.A., Mahfoud, F., Bohm, M., Lambert, G.W., Esler, M.D. and Schlaich, M.P. (2013) Renal Nerve Ablation Reduces Augmentation Index in Patients with Resistant Hypertension. Journal of Hypertension, 31, 1893-1900. http://dx.doi.org/10.1097/HJH.0b013e3283622e58

[31] Brandt, M.C., Mahfoud, F., Reda, S., Schirmer, S.H., Erdmann, E., Bohm, M. and Hoppe, U.C. (2012) Renal Sympathetic Denervation Reduces Left Ventricular Hypertrophy and Improves Cardiac Function in Patients with Resistant Hypertension. Journal of the American College of Cardiology, 59, 901-909. http://dx.doi.org/10.1016/j.jacc.2011.11.034

[32] Lenski, D., Kindermann, I., Lenski, M., Ukena, C., Bunz, M., Mahfoud, F. and Bohm, M. (2013) Anxiety, Depression, Quality of Life and Stress in Patients with Resistant Hypertension before and after Catheter-Based Renal Sympathetic Denervation. EuroIntervention, 9, 700-708.

[33] Lambert, G.W., Hering, D., Esler, M.D., Marusic, P., Lambert, E.A., Tanamas, S.K., Shaw, J., Krum, H., Dixon, J.B., Barton, D.A. and Schlaich, M.P. (2012) Health-Related Quality of Life after Renal Denervation in Patients with Treatment-Resistant Hypertension. Hypertension, 60, 1479-1484.

http://dx.doi.org/10.1161/HYPERTENSIONAHA.112.200865 